\title{
THE ROLE OF EMOTIONAL INTELLIGENCE IN MEDIATING THE RELATIONSHIP BETWEEN EMERGING ADULTHOOD AND ACADEMIC ACHIEVEMENT
}

\author{
Farukh Noor \& Zahyah Hanafi \\ School of Education and Modern Languages \\ Universiti Utara Malaysia, Malaysia
}

Corresponding author: S96173@student.uum.edu.my

\begin{abstract}
Purpose - Academic achievement of students can be fostered and improved if they learn to apply emotional intelligence in their emerging adulthood. The core objective of this research is to test the relationship between emerging adulthood and academic achievement by taking emotional intelligence as a mediator.
\end{abstract}

Methodology - The sample comprises 90 students from Islamia University Bahawalpur, Punjab, Pakistan between the ages 18-25 years. Emerging adulthood characteristics are measured by using the Inventory of the Dimensions of Emerging Adulthood (IDEA), emotional intelligence is measured by using Bar-On EQ-i and academic achievement is measured by Grade Point Average (GPA). Partial least square based structural equational modeling technique (PLS-SEM) is applied to analyze the data.

Findings - The findings show a significant relationship among all the variables in the study and emotional intelligence fully mediates the relationship between emerging adulthood and academic achievement to show that academic achievement of students can be enhanced if they can apply emotional intelligence skills and abilities in their emerging adulthood.

Significance - The study would be valuable for academic institutions to capitalize on emotional intelligence to reduce emotional issues 
among students and attain higher academic achievement and performance.

Keywords: Emotional intelligence (EI), emerging adulthood (EAH), academic achievement (AA), partial least square (PLS).

\section{INTRODUCTION}

Emerging adulthood (EAH) is considered as the period of transition between 18-29 years old. Arnett (2000) termed this age group as emerging adults. Based on Arnett's theory (2000), emerging adulthood is the development period and emerging adults neither consider themselves as adolescents nor adults. During this period, they explore their identity in their work and love, focus on the self and perceive stability due to changes in their status, relationships, work, and education. Therefore, this stage is called the age of possibilities (Arnett, 2014). Arnett has offered five features that are visible in emerging adulthood. According to him, it is not necessary that all emerging adults have these five features, yet these are the characteristics that are prominent throughout emerging adulthood compared to other periods of their life span. As specified by the theory, emerging adulthood is 1 ) the age of identity explorations; 2) the age of instability, 3) the self-focused age, 4) the age of feeling in-between, and 5) the age of possibilities. These five key features generate emerging adulthood, different from adolescence and it is a culturally constructed stage of development (Arnett, 2014; Nelson \& Barry, 2005).

Successful transition into young adulthood requires different developmental tasks; forming independence from a family of origin, achieving emotional autonomy, developing relationships outside the family, creating an adult identity, accepting responsibility for decision making and pursuing education and/or vocational goals (Leavey, 2003; Massey, 2004). However, sometimes, the transition is not easy for emerging adults. Several studies have shown the poor outcomes of emerging adults with disabilities and particularly emotional and behavioural difficulties (Fowler, 2008; Jolivette, Stichter, Nelson, Scott, \& Liaupsin, 2000; Leavey, 2003; Massey, 
2004). The American College Health Association reported in 2011 that depression and anxiety were among the top reasons for decreasing academic achievement in emerging adults. According to their report, $64 \%$ of emerging adults did not attend college because of mental health related reasons such as depression, bipolar disorder, and post-traumatic stress disorder because most emerging adults found this phase of life more complicated, unstable and stressful, and thus might lead to their low academic success. Similarly, in the context of Pakistan, Nadeem, Ali, Maqbool, and Zaidi (2012) researched on the impact of anxiety on the academic achievement of university students in Southern Punjab and declared that anxiety affected academic success of students negatively; as anxiety increases the academic success decreases. Fatima, Shah, and Kiani (2011) also found that most Pakistani students at undergraduate level face challenges in managing their academic affairs and thus they are under severe emotional stress due to far distanced institutions, pathetic classroom environment, and unmotivated teachers.

However, it is not necessary that all emerging adults face problems during this transition period (Buhl, 2007; Galambos, Barker, \& Krahn, 2006). There are some young adults who can handle the distress (Murphy, Blustein, Bohlig, \& Platt, 2010; Perrone \& Vickers, 2003; Polach, 2004). It means that some emerging adults consider this phase of life as an opportunity for knowing about themselves, exploring their identity, trying to achieve emotional autonomy, seeking new ways to succeed in life and taking more responsibility.

The literature also indicates that during this stage, emotions are very intensive, therefore, healthy development of the individual is not possible without controlling over feelings or emotions. Thus, emerging adults with good emotional skills usually feel good about themselves and have a positive relationship with others and develop support networks. They are optimistic about themselves and towards others (Angadi, 2011). According to River, Brackett, Omori, Sickler, Bertoli, and Salovey (2013) emotional skills may help emerging adults to adjust to life and college or university. The question then is, "What if emotional intelligence supports emerging adults in their academic achievement?" Positively better 
self-awareness, empathy, impulse control, optimism and problemsolving skills could probably enhance more persistence, motivation, and achievement, which expectantly would then result in a greater level of perseverance and academic success.

Studies in the field of emotional intelligence are led by three main theories, Salovey and Mayer (1990), Goleman, (1995) and Bar-On, (2000). Salovey and Mayer (1990) termed emotional intelligence as the "ability to monitor one's own and others' feelings and emotions, to discriminate among them and to use this information to guide one's thinking and actions (p. 189)". Goleman wrote in the landmark book, "Emotional Intelligence" in 1995 where he characterized emotional intelligence in terms of "abilities such as being able to motivate oneself and persist in the face of frustration; to control impulse and delay gratification; to regulate one's mood and keep distress from swamping the ability to think; to empathize and to hope" (p.36). Furthermore, Goleman (1995) proposed that emotional intelligence can predict academic success better than traditional measures of intelligence.

On the other hand, Bar-On defined emotional intelligence as "an array of non-cognitive capabilities, competencies and skills that influence one's ability to succeed in coping with environmental demands and pressures" (Bar-On, 1997, p. 14). In 2000, Bar-On presented a model of emotional-social intelligence (ESI) where his model was operationalized by the Emotional Quotient inventory (EQ-i) as being the first measure of its kind to be a self-report measure of emotionally and socially intelligent behaviour. Emotional intelligence may also predict success at work, school and at home. Numerous empirical studies have been conducted in different settings to investigate the relationship between emotional intelligence and students' academic achievement. These studies found that high emotional intelligence gave an added advantage to individuals, be it in educational pursuits or career development (Chew, Zain, \& Hassan, 2013; Jaeger, 2003; Joshi, Srivastava, \& Raychaudhuri, 2012; Petrides, Frederickson, \& Furnham, 2004; Stewart, Chisholm, \& Allen, 2010; Yelkikalan, Hacioglu, Kiray, Ezilmez, Soylemezoglu, Cetin, \& Ozturk, 2012). It has been soundly established that emotional intelligence is one of the important determinants of academic achievement among 
students and this may make them useful employees once they step into the working world.

In the same way, some studies demonstrated that academic achievement was strongly linked with three dimensions of emotional intelligence especially intrapersonal, adaptability, and stress management (Fallahzadeh, 2011; Parker, Saklofske, Shaughnessy, Huang, Wood, \& Eastabrook, 2005; Radfar, Aghaie, Arani, Nooh, \& Saburi, 2013). Similarly, Dastjerdi (2013) and Mohzan, Hassan, and Halil (2013) described that optimism, positive attitude, understanding own emotions and others' emotions and controlling feelings have a positive relationship with academic success. However, there are a few studies that that could not find any impact of emotional intelligence on academic achievement (Javed \& Nasreen, 2014; Kouhsar, Roshan, \& Asqarnejad, 2007; Lawrence \& Deepa, 2013; Meshkat, 2011). Thus, there is a mixed empirical finding between emotional intelligence and academic achievement relationship.

This study also finds a research gap in the literature in that there is no study conducted to the best of the researcher's knowledge to consider all these three important research areas (emerging adulthood, emotional intelligence, and academic achievement) in a single conceptual or empirical model. This is a great opportunity to conceptualize a unified model and seek the impact of emerging adulthood characteristics on academic achievement through emotional intelligence. The present study encompasses the scope of the emerging adulthood literature by investigating the significance of this age period to an eastern country like Pakistan. Moreover, previous studies focused solely on the psychometric properties and presence of EAH phase of life in different countries. Only one study done by Reifman, Arnett, and Colwell (2007) specified a relationship between EAH dimensions and life satisfaction in which they declared that students who scored high on IDEA scale also scored high in life satisfaction scale. Keeping in view their finding, this study investigates the impact of emerging adulthood on the academic achievement of those students who are emerging adults and offers empirical evidence that can be useful to the students to practice emotional intelligence to overcome problems in their emerging adulthood. 


\section{OBJECTIVES}

Based on the above discussion, this study attempts to develop a mediation model in which the emotional intelligence (EI) is a mediator between emerging adulthood (EAH) and academic achievement (AA) relationship, to show that the emerging adults can perform better in their academic performance by utilizing their EI skills. In addition, academic institutions may improve the academic success of the emerging adults through a better understanding of their emotional intelligence. This study attempts to be the pioneer that examines the relationship between emerging adulthoods and academic achievement through the emotional intelligence of students.

\section{Research Question}

The study is built on a simple proposition that emerging adults' academic performance can be improved through increasing their emotional intelligence. Thus, the research question is, how does emotional intelligence as a mediator affect the relationship between emerging adulthood and academic performance?

\section{Research Framework}

The theoretical framework of this study is based on two theories: Bar-On EQ-i and Arnett theory of emerging adulthood. It is argued that emerging adulthood phase of life of students is characterized by six dimensions and affected by several emotional and social factors. Therefore, the learning of emotional intelligence skills and abilities in emerging adulthood may increase their academic capabilities and improve their academic achievement. The research framework is shown in figure 1.

In this model, EAH means emerging adulthood and it acts as an independent variable, AA means academic achievement and it acts as the dependent variable and EI means emotional intelligence and it acts as a mediator. 


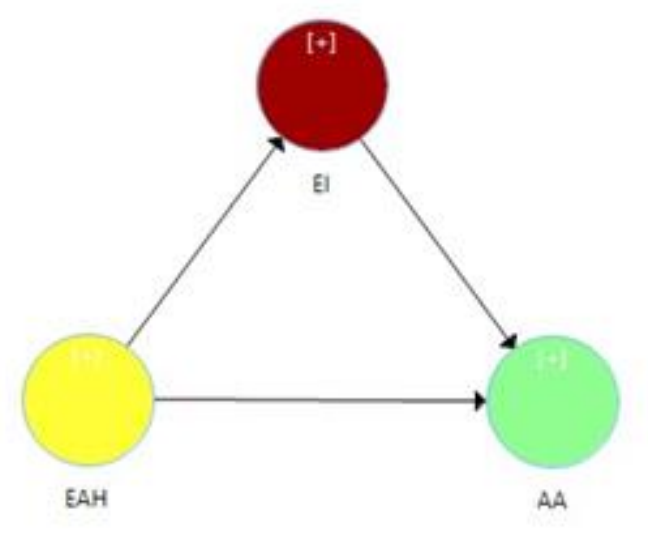

Figure 1. Mediating model

\section{METHODOLOGY}

\section{Participants}

The respondents of this study are 90 students from the Islamia University Bahawalpur, Pakistan. They were in their $2^{\text {nd }}$ semester and were selected by using random sampling approach. Their background information was gathered through student demographic survey (SDS) to determine their demographics. In particular, one Question ("Do you think that you have reached adulthood? (yes, no, in between") was added at the end of SDS to determine whether they are perceived as adults or emerging adults (Arnett, 2015; Badger, Nelson \& Barry, 2006). The students were then asked to answer this question by keeping in mind three conditions i.e. acceptance of responsibility, making independent decisions and becoming financially independent, as these are the top conditions for adulthood (Arnett, 1998, 2002, 2003, 2004; Facio \& Micocci, 2003; Mayseless \& Scharf, 2003; Nelson, Bedger, \& Wu, 2004). The students who answered "yes" are considered as perceived adult. Students who answered "no" and "in between" are considered as emerging adults. In this research, 26 (28.8\%) students have answered in "Yes", 10 $(11.11 \%)$ have answered in "No" and $54(60 \%)$ have provided the ambiguous response "in between". Therefore, $64(71.11 \%)$ students have been selected as emerging adults and were given IDEA 
inventory to be filled out. In comparison, in the USA, $72 \%$ students and in China $41 \%$ students were selected as emerging adults after answering the same question (Badger, Nelson, \& Barry, 2006).

\section{Instrument}

In this study, emerging adulthood is measured by the Inventory of Dimensions of Emerging Adulthood (IDEA). It is a self-reported measurement with 31 questions. The IDEA has already been used to measure emerging adulthood in college students from Israel, Argentina, and the United States (Atak \& Cok, 2008) Australia (Bell, \& Lee, 2005, 2008; Hawkinsa, Letcher, Sanson, Smart, \& Toumbourou, 2009), China (Nelson et al., 2004, Nelson, PadillaWalker, Carroll, Madsen, McNamara, \& Badger, 2007), India (Seiter \& Nelson, 2011), and Malaysia (Wider, Mustapha, \& Bullare, 2015). It makes IDEA an inventory intended to be used by emerging adults, universally. The IDEA is offered in a self-report, four-point Likert-scale format ( 1 = Strongly Disagree, $4=$ Strongly Agree) . The highest probable score is 124 and the least is 31 .

Bar-On Emotional Quotient Inventory (EQ-i) (Bar-On, 1997) is a standardized instrument to measure different aspects of emotional intelligence. The original instrument had 133 questions with five composite scales and 15 subscales that constitute the total EQ score. The raw score of EI is converted into standardized EI score at a mean of 100 and standard deviation of 15 (Bar-On, 2006). The EQ-i is one of the most extensively used measures of trait emotional intelligence in the research field. The EQ-i covers the sampling domain of the trait for emotional intelligence better than other inventories (Petrides \& Furnham, 2001; Bar-On, 2006). In this study, Bar-On EQ-I is used which is comprised of 117 questions. Its reliability and validity were examined by Aslam (2004) in the Pakistani context. GPAs are collected from the respective examination departments of the respondents. The reliability and validity of academic achievement indicator, GPA and a standardized score of EI (for EI construct) are also established by content validity through literature review. Finally, student's demographic profile is collected through the student demographic survey (SDS) questionnaire. 


\section{FINDINGS}

\section{Analysis}

This study uses SmartPLS version 3.2.1 to analyze the data. Firstly, the descriptive statistics of all the variables in the study was calculated for preliminary analysis of mean, median, standard deviation, minimum and maximum values to identify any dissimilarity in the data set. The detail of descriptive statistics is given in Table 1.

Table 1

Descriptive Statistics

\begin{tabular}{lccccc}
\hline \multicolumn{1}{c}{ Description } & No & Min & Max & Mean & Std. Deviation \\
\hline ID_EXP & 64 & 15 & 27 & 22.27 & 3.08 \\
EXP_POS & 64 & 9 & 20 & 16.17 & 2.59 \\
NEG_INS & 64 & 7 & 26 & 18.88 & 3.82 \\
O_FOC & 64 & 4 & 12 & 9.11 & 1.74 \\
S_FOC & 64 & 11 & 24 & 19.06 & 3.03 \\
F_I_B & 64 & 3 & 12 & 8.70 & 1.96 \\
GPA & 64 & 2.04 & 3.99 & 3.42 & 0.39 \\
EI & 64 & 71.35 & 128.19 & 100 & 15 \\
\hline
\end{tabular}

Notes: ID_EXP: Identity Exploration EXP_POS: Experimentation and Possibilities, NEG_INS: Negativity and Instability, O_FOC: Other Focus, S_FOC: Self-Focus, F_I_B: Feeling In Between, GPA: Grade Point Average, EI: Emotional Intelligence.

Table 1 shows the descriptive output related to the six subscales of emerging adulthood. As there are no extreme values in the dataset, the arithmetic mean is used as the measure of central tendency. The measure of dispersion used in this study is the standard deviation. The average values of subscales of emerging adulthood range from 8.70 to 22.27 which is due to the different number of items in the different subscales.

The descriptive statistics also reveals that GPA of emerging adults falls in the range of 2.04 to 3.99 and the average GPA is 3.42 which shows significant contribution of emerging adults to their academic performance. The emotional intelligence score 
is calculated by taking a mean of 100 and a standard deviation of 15 (Bar-On, 2006) which is called emotional intelligence standardized score. This score provides an overall sign of how emotionally intelligent the respondent is; i.e., means how effective the individual is at identifying and expressing oneself, developing and maintaining social relationships, coping with challenges, and using emotional information in an effective and meaningful way. As per this score, the students who scored 130 or above are termed as exceptionally high emotional intelligent students, 110-129 score means high emotional intelligence, the 90-109 score represents average emotional intelligence and below 90 score means below average emotional intelligence. In this study, 19 students fall in the category of high emotional intelligence ranging from 111.56 to 128.19 , only 21 students in average emotional intelligence category ranging from 90.09 to 109.45 and the remaining 24 students are below the average category of emotional intelligence ranging from 71.35 to 89.79 . Overall, 38 students have scored below 100 which requires urgent need of training and learning of emotional intelligence abilities (Multi-Health Systems, 2011)

Furthermore, $60 \%$ respondents are female students as the numbers of female students are rising in universities for the last few years and male students are decreasing in number. The $66 \%$ students live in the urban areas and $36 \%$ belong to rural areas. Usually, in Pakistan, universities are in urban areas and parents from rural areas move to urban areas for the study purposes of their children. On average, there are 4 siblings of students that represent the middle-sized family in Pakistan. The average income of parents falls in the category of 500 to 600 US\$, monthly thus, showing middle-class family income. The fathers of students are more educated than their mothers as most mothers stay at home to look after their family.

In this study, the role of EI as mediator is tested. It is found that EI fully mediates the relationship between EAH and AA. The PLSSEM analysis is comprised of two types of analysis; one is called measurement analysis and the second is called structural analysis. In the measurement analysis, there are two types of models; reflective measurement model and formative measurement model. However, this study will only use the formative measurement 
model approach as all the indicators are formative in nature after following the guidelines of Hair, Hult, Ringle, and Sarstedt (2014). The formative measurement model requires reliability and validity of the indicators and its respective construct through collinearity and significance of indicators tests (Ringle, Wende, \& Will, 2010).

\section{Formative Measurement Model}

In this study, the EAH is taken as a higher order or second order construct which consists of six lower or first order constructs namely ID_EXP: identity exploration EXP_POS: Experimentation/ Possibilities, NEG_INS: Negativity/instability, O_FOC: other Focus, S_FOC: self-focus, F_I_B: feeling in between. The analysis of PLS for higher order construct is run through repeated indicator approach. In this approach, all the indicators are attached with the second order construct, initially, and then the first order constructs along with their respective indicators are developed and attached with the second order construct (Hair et al., 2014). In Table 2, the collinearity between indicators of first order constructs (subscales of EAH) is tested through VIF by using SmartPLS and there was no indication of collinearity among the indicators. All the values are below the critical threshold of VIF $=<5.0$ (Hair et al., 2014).

Table 2

VIF Values

\begin{tabular}{lcccrr}
\hline Indicators & VIF & Indicators & VIF & Indicators & VIF \\
\hline E-Pos 1 & 1.237 & Id-Ex 4 & 1.44 & O-Foc 1 & 1.007 \\
E-Pos 2 & 1.274 & Id-Ex 5 & 2.143 & O-Foc 2 & 1.074 \\
E-Pos 3 & 1.625 & Id-Ex 6 & 1.784 & O-Foc 3 & 1.076 \\
E-Pos 4 & 1.144 & Id-Ex 7 & 1.394 & S-Foc 1 & 1.304 \\
E-Pos 5 & 1.361 & N-Ins 1 & 1.444 & S-Foc 2 & 1.826 \\
F-I-B 1 & 1.483 & N-Ins 2 & 1.412 & S-Foc 3 & 1.192 \\
F-I-B 2 & 1.399 & N-Ins 3 & 1.782 & S-Foc 4 & 1.724 \\
F-I-B 3 & 1.118 & N-Ins 4 & 1.271 & S-Foc 5 & 1.178 \\
Id-Ex 1 & 1.343 & N-Ins 5 & 1.643 & S-Foc 6 & 1.262 \\
Id-Ex 2 & 1.315 & N-Ins 6 & 1.201 & EI-S-Score & 1 \\
Id-Ex 3 & 1.572 & N-Ins 7 & 1.292 & GPA & 1 \\
\hline
\end{tabular}


As seen in Table 2, the outer VIF values for each indicator of first order constructs, ID_EXP, EXP_POS, NEG_INS, O_FOC, S_ FOC and F_I_B, do not show any sign of collinearity among them. This means that all indicators are independent of each other and are reliable to be used in the study. To show the validity of data, the significance of indicators of first order constructs (subscales of EAH) to academic achievement is tested through their t-values and p-values by running biased corrected and accelerated bootstrapping of 5000 resamples with replacement approach in SmartPLS 3.2.1, as shown in Table 3.

Table 3

Indicators Validity Test of First Order Constructs

\begin{tabular}{|c|c|c|c|c|}
\hline $\begin{array}{l}\text { First order } \\
\text { constructs }\end{array}$ & Indicators & $\begin{array}{l}\text { outer weights } \\
\text { (loadings) }\end{array}$ & $\begin{array}{l}\text { T-values (sig. of outer } \\
\text { weights or loadings } \\
\text { whichever is higher) }\end{array}$ & P-Values \\
\hline \multirow{5}{*}{ EXP-POS } & E-Pos 1 & $0.109(0.277)$ & 1.272 & 0.204 \\
\hline & E-Pos 2 & $0.190(0.542)$ & $2.388 * *$ & 0.017 \\
\hline & E-Pos 3 & $-0.018(0.568)$ & $3.220 * * *$ & 0.001 \\
\hline & E-Pos 4 & $0.567(0.620)$ & $3.011 * * *$ & 0.003 \\
\hline & E-Pos 5 & $0.697(0.754)$ & $3.795 * * *$ & 0.000 \\
\hline \multirow{3}{*}{ F-I-B } & F-I-B 1 & $0.2319(0.749)$ & $2.702 * * *$ & 0.007 \\
\hline & F-I-B 2 & $0.503(0.784)$ & $2.912 * * *$ & 0.004 \\
\hline & F-I-B 3 & $0.509(0.721)$ & $2.622 * * *$ & 0.009 \\
\hline \multirow{7}{*}{ ID-EXP } & Id-Ex 1 & $0.294(0.499)$ & $3.295 * * *$ & 0.001 \\
\hline & Id-Ex 2 & $-0.120(0.127)$ & 0.907 & 0.365 \\
\hline & Id-Ex 3 & $0.336(0.611)$ & $3.694 * * *$ & 0.000 \\
\hline & Id-Ex 4 & $0.368(0.729)$ & $5.256 * * *$ & 0.000 \\
\hline & Id-Ex 5 & $-0.056(0.654)$ & $4.627 * * *$ & 0.000 \\
\hline & Id-Ex 6 & $0.420(0.782)$ & $6.060 * * *$ & 0.000 \\
\hline & Id-Ex 7 & $0.201(0.511)$ & $2.718 * * *$ & 0.007 \\
\hline \multirow{4}{*}{ NEG-INS } & N-Ins 1 & $-0.039(0.237)$ & 1.295 & 0.196 \\
\hline & N-Ins 2 & $-0.003(0.277)$ & 1.559 & 0.120 \\
\hline & N-Ins 3 & $-0.045(0.276)$ & 1.523 & 0.128 \\
\hline & N-Ins 4 & $-0.158(0.038)$ & 0.234 & 0.815 \\
\hline
\end{tabular}




\begin{tabular}{|c|c|c|c|c|}
\hline $\begin{array}{l}\text { First order } \\
\text { constructs }\end{array}$ & Indicators & $\begin{array}{l}\text { outer weights } \\
\text { (loadings) }\end{array}$ & $\begin{array}{l}\text { T-values (sig. of outer } \\
\text { weights or loadings } \\
\text { whichever is higher) }\end{array}$ & P-Values \\
\hline \multirow{3}{*}{ NEG-INS } & N-Ins 5 & $0.592(0.783)$ & $3.599 * * *$ & 0.000 \\
\hline & N-Ins 6 & $0.651(0.840)$ & $4.171 * * *$ & 0.000 \\
\hline & N-Ins 7 & $0.061(0.298)$ & $1.776^{*}$ & 0.076 \\
\hline \multirow{3}{*}{ O-FOC } & O-Foc 1 & $0.692(0.748)$ & $3.955 * * *$ & 0.000 \\
\hline & O-Foc 2 & $0.422(0.571)$ & $2.443 * *$ & 0.015 \\
\hline & O-Foc 3 & $0.418(0.578)$ & $2.724 * * *$ & 0.007 \\
\hline \multirow{6}{*}{ S-FOC } & S-Foc 1 & $0.127(0.374)$ & $1.891 *$ & 0.059 \\
\hline & S-Foc 2 & $0.287(0.751)$ & $4.482 * * *$ & 0.000 \\
\hline & S-Foc 3 & $0.276(0.587)$ & $3.211 * * *$ & 0.001 \\
\hline & S-Foc 4 & $0.345(0.695)$ & $4.427 * * *$ & 0.000 \\
\hline & S-Foc 5 & $0.314(0.506)$ & $2.437 * * *$ & 0.015 \\
\hline & S-Foc 6 & $0.326(0.542)$ & $2.617 * * *$ & 0.009 \\
\hline
\end{tabular}

* Significance at $10 \%(1.645) . * *$ Significance at $5 \%(1.96) . * * *$ Significance at $1 \%(2.576)$

Table 3 reports the significance of the indicators on all the subscales of emerging adulthood. The significance of outer weights for formative indicators is a necessary test to validate the indicators (Hair et al., 2014). However, if any indicator weight is not significant then its outer loading significance should be tested to decide whether to remove or retain that indicator. In this study, some of the indicators' weights are significant in each subscale but the outer loadings of almost every indicator are significant except E-Pos1, Id-Ex2, N-Ins1, N-Ins2, N-Ins3 and N-Ins4 which are non-significant (Table 3). However, these are kept for further analysis as their removal does not affect the whole model and its parameter values. Moreover, these are the indicators of IDEA inventory which cannot be removed based on statistical reasoning only (Diamantopoulos \& Siguaw, 2006; Jarvis, MacKenzie, \& Podsakoff, 2003). Removing any formative single indicator may alter the meaning and scope of the whole construct as it occupies the specific part of the construct (Jarvis et al., 2003; MacKenzie, \& Royle, 2005).

As the second step for analysis of second-order construct, the VIF values for subscales of emerging adulthood are tested and 
no indication of collinearity among its subscales is found. The significance of weights for each subscale to form emerging adulthood is also tested and found significant. The results of VIF and weights, their t-values and p-values of second order construct on emerging adulthood are given in Table 4.

Table 4

VIF and Significance of Second Order Construct

\begin{tabular}{cccccc}
\hline $\begin{array}{c}\text { Second order } \\
\text { constructs }\end{array}$ & $\begin{array}{c}\text { First order con- } \\
\text { structs }\end{array}$ & $\begin{array}{c}\text { outer } \\
\text { weights }\end{array}$ & t-values & p-values & VIF \\
\hline \multirow{6}{*}{ EAH } & EXP-POS & 0.175 & $2.794 * * *$ & 0.005 & 1.694 \\
& F-I-B & 0.153 & $2.612 * * *$ & 0.009 & 1.220 \\
& ID-EXP & 0.374 & $4.413 * * *$ & 0.000 & 2.587 \\
& NEG-INS & 0.144 & $2.036 * *$ & 0.042 & 1.878 \\
& O-FOC & 0.276 & $4.393 * * *$ & 0.000 & 1.619 \\
& S-FOC & 0.173 & $2.264 * *$ & 0.024 & 2.905 \\
\hline
\end{tabular}

* Significance at $10 \%(1.65)$. ** Significance at 5\% (1.96). *** Significance at $1 \%(2.58)$

Based on Table 4, the weights of the subscales of the second order construct on emerging adulthood are found to be significant at $\mathrm{p}<$ 0.05 level and VIF values are also below the maximum value of 5.0 as shown above. The findings also show the contribution and significance for each subscale in making the emerging adulthood. It reveals a significant relationship between second-order construct EAH and its respective first order constructs; EXP-POS, F-I-B, IDEXP, NEG-INS, O-FOC and S-FOC at $\mathrm{p}<0.05$, thus, confirming the subscales of emerging adulthood. The weight of ID-EXP is the largest at 0.374 followed by O-FOC at 0.276 . The lowest weight is NEG-INS at 0.144. Thus, it is established that the six subscales of emerging adulthood are formative constructs, thereby confirming nomological validity.

\section{Formative Structural Model}

The structural model analysis consists of the significance of path coefficients, the level of $\mathrm{R}^{2}$ and predictive relevance $\mathrm{Q}^{2}$ (Hair et al., 
2014). The path coefficients, $R^{2}$ values and mediation of EI is seen through the structural model of EAH, EI and AA (Figure 2).

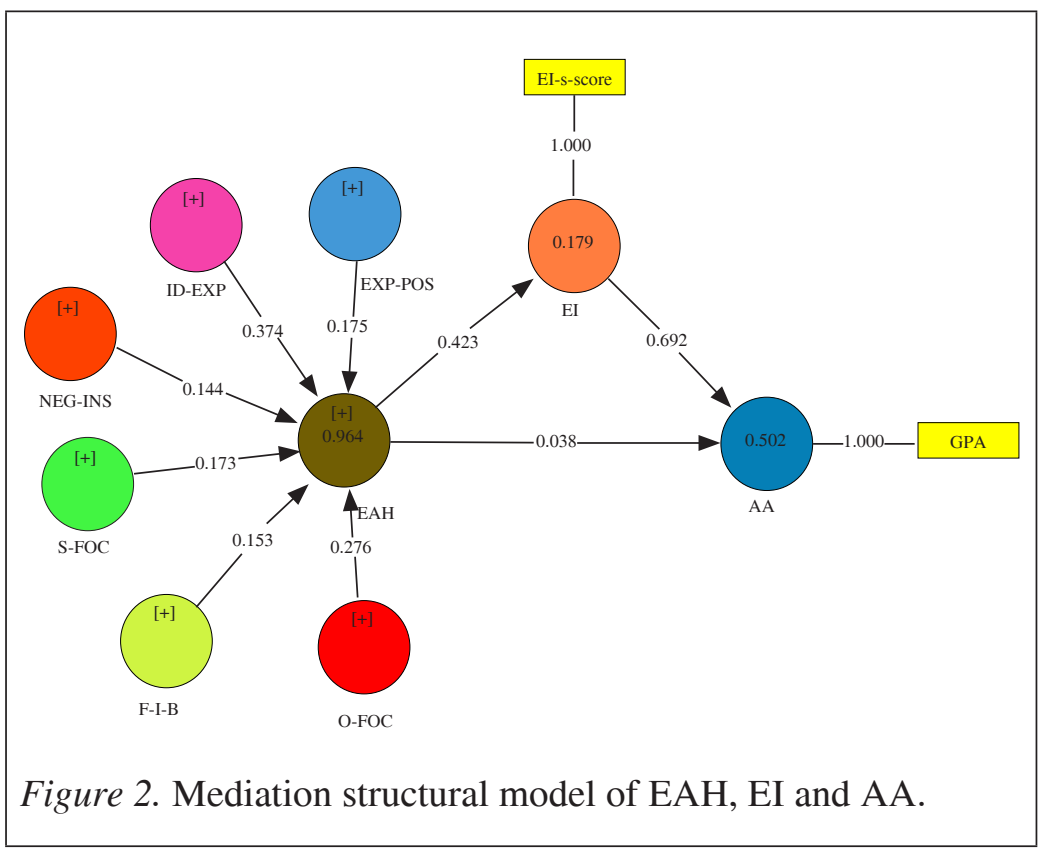

The significance of path coefficients is determined by Bias Corrected and Accelerated bootstrapping approach of 5000 samples with replacement in SmartPLS and is given in table 5.

Table 5

Significance of Path Coefficient, $R^{2}$, Adjusted $R^{2}, f^{2}$ and $Q^{2}$

\begin{tabular}{lccccccc}
\hline Relationship & Path coefficient & t-value & p value & $\mathrm{R}^{2}$ & Ad. $R^{2}$ & $\mathrm{f}^{2}$ & $\mathrm{Q}^{2}$ \\
\hline EAH $>$ AA & 0.038 & 0.39 & 0.60 & & & & \\
EAH $>$ EI & 0.423 & $3.77 * * *$ & 0.000 & & & & \\
EI $>$ AA & 0.692 & $7.55^{* * *}$ & 0.000 & & & & \\
EAH $>$ EI $>$ AA & 0.292 & $3.38^{* * *}$ & 0.000 & 0.50 & 0.50 & 1.0 & 0.467 \\
\hline
\end{tabular}

*** Significance at $1 \%(2.57)$

Table 5 and figure 2 show that by adding EI as a mediator between $\mathrm{EAH}$ and AA, the academic performance of emerging adults is enhanced (for brevity purpose, the positive significant relationship 
between EAH and academic achievement is not shown, but can be provided, if needed). The direct effect of EAH and AA becomes insignificant to 0.038, (t-value 0.39) and the indirect effect becomes significant $(0.423 \times 0.692=0.292$, t-value 3.38$)$, which demonstrates full mediation of EAH and AA through EI (Baron \& Kenny, 1986). The magnitude of mediation is calculated by variance accounted for (VAF) and it is equal to the indirect effect divided by the total effect $\{0.292 /(0.292+0.038)\}=0.88)$. It is found that full mediation exists as the value of VAF above 0.80 shows full mediation (Hair et al., 2014). The concluding $\mathrm{R}^{2}$ value and adjusted $\mathrm{R}^{2}$ values are the same as 0.50 , showing the appropriateness of indicators and constructs used in the model. Moreover, 0.50 value is above the large effect size and displays the promising explanatory power of this model. In addition, the $\mathrm{f}^{2}$ value 1.00 is also calculated which shows the large effect size. The predictive relevance of this model is also quite significant as the $\mathrm{Q}^{2}$ is 0.467 above the acceptable value of above than zero.

\section{DISCUSSION AND CONCLUSION}

The empirical result of this study provides ample evidence that Inventory of Dimensions of Emerging Adulthood (IDEA) truly consists of six subscales and the identity exploration contributes the highest value, followed by other-focus. The negativity or instability contributes the least value to the EAH in making its relationship with EI and AA. The emotional intelligence has a strong mediating effect on the relationship between emerging adulthood and academic achievement. It may mean that emotional intelligence (EI) helps the emerging adults to reduce their negativity or instability and feeling in-between situations and encourages them to explore their identity and future opportunities as well.

The relationship between EAH and EI is positively significant which shows that students high in their EAH also have higher emotional intelligence. The result reveals that emerging adulthood characteristics especially, identity exploration, other focus, experimentation or possibilities and self-focus have more significant, positive relationships to emotional intelligence which in turn enhances the academic performance of the students. According 
to Mayer, Roberts, and Barsade (2008), emerging adults with high emotional intelligence might be ready to sort out and manage emotion-laden circumstances, which eventually reduce their involvement in risk-taking matters. Consequently, emerging adults with good emotional skills usually feel good about themselves and have a positive relation with others and develop support networks. They are optimistic about themselves and towards others (Gillies \& Robinson, 2010; Angadi, 2011).

The identity exploration dimension of EAH contributes the highest weight in developing its relationship with the EI and AA. Arnett (2015) describes identity exploration to be related to love, job and worldviews, along with general ideas of how to build a life. It means that Pakistani emerging adults feel positive in their emerging adulthood and try to explore their identity, start taking responsibility for their love or job life. They enjoy autonomy in their decision making, emotional desires, relationships and future objectives. That is why their emotional wellbeing is more stable and healthy which affects their academic achievement positively. The second dimension of EAH that contributes significantly to the EI and academic achievement is the other focus which shows that Pakistani student takes responsibility and fulfill their commitment to others. Pakistan is a conservative society where people live in joint families and share responsibilities for the exchange of loyalty. The third dimension of EAH, experimentation/possibilities also has significant and positive relationship towards EI and AA. It means that, in their emerging adulthood, they are optimistic about their future. Similarly, the self-focus dimension gives the opportunity to do what they like to do and where they want to go with their friends. This freedom about themselves understanding and expressing their emotions which make them self-confident and energetic, affecting their academic performance positively.

Similarly, the relationship between EI and academic achievement is also positively significant, showing that higher EI leads to higher AA, because high emotional intelligence gives an added advantage to individuals, whether in educational pursuit or career development (Akbar, Shah, Khan, Akhter, \& Riaz, 2011; Chew et al., 2013; Fatima, Shah, \& Kiani, 2011; Parker et al., 2005; Yelkikalan et al., 2012). 
The current study extends the scope of the emerging adulthood literature by not only examining the presence and significance of this life period in an eastern country like Pakistan but also testing the role of emotional intelligence in enhancing the academic achievement of students in their emerging adulthood phase of life. As per authors' knowledge, this is the first study conducted in Pakistan on emerging adulthood. Moreover, this study takes an initial step and provides an opportunity to examine the role of emotional intelligence as a mediator in the relationship of emerging adulthood and academic achievement. It is an important step because it benefits the emerging adults as well as the academic institutions. The methodological strength of this study is that formative-formative higher order construct model is applied in PLS-SEM, that has not been used in other studies.

Nevertheless, there are some limitations found in this study. Firstly, it is a country and university specific study and the sample size is also small. It is advisable to extend the sample size as well as include more universities and countries as this would reflect the cross-cultural effects of this model. The higher order formativeformative model needs to be validated across different settings. Secondly, in this study, only IDEA inventory is used to access the emerging adulthood which is a self-reported measure and result could be subjected to the respondents' bias.

Consequently, through this study, it can be concluded that emotional intelligence significantly mediates the relationship of emerging adulthood and academic achievement of university students. Emotional abilities help emerging adults to deal in a better way with their difficulties and emotional, behavioural problems which they face in their emerging adulthood phase. Hence, these emotional abilities help them to eventually improve their academic achievement. Educational institutions may arrange some programs of training in emotional skills for emerging adults so that they can easily and effectively cope with their problems. Certainly, the findings of this research have also reported a psychometric result as compared to prior studies which had used the reflective measurement models and removed or changed the indicators of emerging adulthood due to indigenous reasons. This study also suggests that future researchers may use IDEA in their study with the option of 
using EAH as a formative construct rather than reflective as there is substantial evidence to show that EAH construct is formative in nature.

\section{REFERENCES}

Akbar, M., Shah, A. A., Khan, E. A., Akhter, M., \& Riaz, M. N. (2011). Relationship between emotional intelligence and academic achievement among higher secondary school students. Pakistan Journal of Psychology, 42(2), 43-56.

Aslam, F. (2004). Relationship between emotional intelligence and occupational stress among Informational Technology Professionals (Unpublished doctoral dissertation). National Institute of Psychology, Quaid-e-Azam University, Islamabad. Angadi, A. S. (2011). Emotional health of emerging adults. (Unpublished doctoral dissertation). University of Agricultural Sciences, Dharwad.

Arnett, J. J. (1998). Learning to stand alone: The contemporary American transition to adulthood in cultural and historical context. Human Development, 41, 295-315.

Arnett, J. J. (2000). Emerging adulthood: A theory of development from the late teens through the twenties. American Psychologist, 55(5), 469.

Arnett, J. J. (2002). The psychology of globalization. American Psychologist, 57(10), 774.

Arnett, J. J. (2003). Conceptions of the transition to adulthood among emerging adults in American ethnic groups. New Directions for Child and Adolescent Development, (100), 63-76.

Arnett, J. J. (2004). Emerging adulthood: The winding road from the late teens through the twenties. New York, NY: Oxford University Press.

Arnett, J. J. (2014). Emerging adulthood: The winding road from the late teens through the twenties (2nd ed.). New York, NY: Oxford University Press.

Atak, H., \& Cok, F. (2008). The Turkish version of inventory of the dimensions of emerging adulthood (The IDEA). International Journal of Humanities and Social Sciences, 2(3), 148-154.

Badger, S., Nelson, L. J., \& Barry, C. M. (2006). Perceptions of the transition to adulthood among Chinese and American emerging adults. International Journal of Behavioral Development, 30(1), 84-93. 
Bar-On, R. (2000). Emotional and Social Intelligence: Insight from the emotional quotient inventory. The Handbook of Emotional Intelligence (pp. 343-362), San Francisco: Jossey-Bass.

Bar-On, R. (1997). The Emotional Quotient Inventory (EQ-i): A test of emotional intelligence. Toronto: Multi-Health Systems, 28.

Bar-On, R. (2006). The Bar-On model of emotional-social intelligence (ESI). Psicothema, 18, Suppl.13-25.

Baron, R. M., \& Kenny, D. A. (1986). The moderator-mediator variable distinction in social psychological research: Conceptual, strategic, and statistical considerations. Journal of personality and social psychology, 51(6), 1173.

Bell, S., \& Lee, C. (2005). Emerging adulthood and patterns of physical activity among young Australian women. International Journal of Behavioral Medicine, 12(4), 227-235.

Bell, S., \& Lee, C. (2008). Transitions in emerging adulthood and stress among young Australian women. International Journal of Behavioral Medicine, 15(4), 280-288.

Buhl, H. M. (2007). Well-being and the child-parent relationship at the transition from university to work life. Journal of Adolescent Research, 22(5), 550-571.

Chew, B. H., Zain, A. M., \& Hassan, F. (2013). Emotional intelligence and academic performance in first and final year medical students: a cross-sectional study. BMC Medical Education 2013, 13(44), 2-10.

Dastjerdi, N. B. (2013). The Relationship between Emotional Intelligence and Academic Achievement of Students in Virtual Courses in Iran. Journal of American Science, 9(6), 466-470.

Diamantopoulos, A., \& Siguaw, J. A. (2006). Formative versus reflective indicators in organizational measure development: A comparison and empirical illustration. British Journal of Management, 17(4), 263-282.

Facio, A., \& Micocci, F. (2003). Emerging adulthood in Argentina. New Directions for Child and Adolescent Development, 2003(100), 21-32.

Fallahzadeh, H. A. (2011). The Relationship between Emotional Intelligence and Academic Achievement in medical science students in Iran. Social and Behavioral Sciences, 30, 1461 - 1466. 
Fatima, N., H Shah, S. M., \& Kiani, A. (2011). An Empirical Evidence of Relationship between Emotional Intelligence (EI) and Academic Achievement (AA) of Undergraduate Students. International Journal of Education and Social Sciences (IJESS), 1(3).

Fowler, K. M. (2008). Transition experiences of selected emerging adults with emotional and behavioral difficulties in higher education. (Unpublished Ph.D. thesis), University of South Florida.

Galambos, N. L., Barker, E. T., \& Krahn, H. J. (2006). Depression, self-esteem, and anger in emerging adulthood: seven-year trajectories. Developmental psychology, 42(2), 350.

Gillies, V., \& Robinson, Y. (2010). Managing emotions in research with challenging pupils. Ethnography and Education, 5(1), 97-110.

Goleman, D. (1995). Emotional intelligence. New York: Bantam.

Hair, J. F., Hult, G. T. M., Ringle, C. M., \& Sarstedt, M. (2014). A Primer on Partial Least Squares Structural Equation Modeling (PLS-SEM). Thousand Oaks: Sage.

Hawkins, M. T., Letcher, P., Sanson, A., Smart, D., \& Toumbourou, J. W. (2009). Positive development in emerging adulthood. Australian Journal of Psychology, 61(2), 89-99.

Jaeger, A. J. (2003). Job competencies and the curriculum: An inquiry into emotional intelligence in graduate professional education. Research in Higher Education, 44(6), 615-639.

Jarvis, C. B., MacKenzie, S. B., \& Podsakoff, P. M. (2003). A critical review of construct indicators and measurement model misspecification in marketing and consumer research. Journal of Consumer Research, 30(2), 199-218.

Javed, N., \& Nasreen, A. (2014). The role of emotional intelligence in academic performance of male and female students in the University of the Punjab. Journal of Education and Practice, 5(4), 32-35.

Jolivette, K., Stichter, J. P., Nelson, C. M., Scott, T. M., \& Liaupsin, C. J. (2000). Improving Post-School Outcomes for Students with Emotional and Behavioral Disorders. ERIC/OSEP Digest E597.

Joshi, S. V., Srivastava, K., \& Raychaudhuri, A. (2012). A descriptive study of emotional intelligence and academic performance of MBBS students. Procedia-Social and Behavioral Sciences, 69, 2061-2067. 
Kouhsar, A, Roshan, R, \& Asqarnejad, A. (2007). Comparative study of the relation between emotional intelligence and mental health and academic achievements in Shahed and state students of Tehran University. Psychology and Educative Science.

Lawrence, A., \& Deepa, T. (2013). Emotional Intelligence and academic achievement of high school students in Kanyakumari district. Online Submission, 3(2), 101-107.

Leavey, J. E. (2003). The meaning of mental illness to youth: Exploring the psychosocial effects of mental illness on identity and life cycle development in youth aged 17-24 (Unpublished doctoral dissertation). University of Toronto.

MacKenzie, D. I., \& Royle, J. A. (2005). Designing occupancy studies: general advice and allocating survey effort. Journal of Applied Ecology, 42(6), 1105-1114.

Massey, S. A. (2004). Young adults with mental illness who are transitioning into adulthood and the specific needs common to this population: A critical review of the literature. (Unpublished Ph.D. dissertation), Alliant International University, California School of Professional Psychology, San Diego.

Mayseless, O., \& Scharf, M. (2003). What does it mean to be an adult? The Israeli experience. New directions for child and adolescent development, 2003(100), 5-20.

Mayer, J. D., Roberts, R. D., \& Barsade, S. G. (2008). Human abilities: Emotional intelligence. Annu. Rev. Psychol., 59, 507-536.

Meshkat, M. (2011). The relationship between emotional intelligence and academic success. Journal of Technology \& Education, 5(3), 201-204.

Mohzan, M. A. M., Hassan, N., \& Halil, N. A. (2013). The Influence of Emotional Intelligence on Academic Achievement. Social and Behavioral Sciences, 90, 303-312.

Multi-Health Systems, Inc. (2011). EQ-i 2.0® Technical Manual. Toronto, Canada: Multi-Health Systems, Inc.

Murphy, K. A., Blustein, D. L., Bohlig, A. J., \& Platt, M. G. (2010). The College-to-Career Transition: An Exploration of Emerging Adulthood. Journal of Counseling \& Development, 88(2), 174-181. 
Nadeem, M., Ali, A., Maqbool, S., \& Zaidi, S. U. (2012). Impact of anxiety on the academic achievement of students having different mental abilities at the university level in Bahawalpur (southern Punjab) Pakistan. International Online Journal of Educational Sciences, 4(3), 519-528.

Nelson, L. J., Badger, S., \& Wu, B. (2004). The influence of culture in emerging adulthood: Perspectives of Chinese college students. International Journal of Behavioral Development, 28, 26-36.

Nelson, L. J., \& Barry, C. M. (2005). Distinguishing features of emerging adulthood the role of self-classification as an adult. Journal of Adolescent Research, 20(2), 242-262.

Nelson, L. J., Padilla-Walker, L. M., Carroll, J. S., Madsen, S. D., McNamara Barry, C., \& Badger, S. (2007). If you want me to treat you like an adult, start acting like one!" Comparing the criteria that emerging adults and their parents have for adulthood. Journal of Family Psychology, 21(4), 665-674.

Parker, J. D. A., Saklofske, D. H., Shaughnessy, P. A., Huang, S. H. S., Wood, L. M., \& Eastabrook, J. M. (2005). Generalizability of the emotional intelligence construct: A cross-cultural study of North American aboriginal youth. Personality and Individual Differences, 39, 215-227.

Perrone, L., \& Vickers, M. H. (2003). Life after graduation as a "very uncomfortable world": an Australian case study. Education+ Training, 45(2), 69-78.

Petrides, K. V., Frederickson, N., \& Furnham, A. (2004). The role of trait emotional intelligence in academic performance and deviant behavior at school. Personality and Individual Differences, 36(2), 277-293.

Petrides, K. V., \& Furnham, A. (2001). Trait emotional intelligence: Psychometric investigation with reference to established trait taxonomies. European Journal of Personality, 15(6), 425-448.

Polach, J. L. (2004). Understanding the experience of college graduates during their first year of employment. Human Resource Development Quarterly, 15(1), 5-23.

Pope, D., Roper, C., \& Qualterb. P. (2012). The influence of emotional intelligence on academic progress and achievement in UK university students. Assessment \& Evaluation in Higher Education, 37(8), 907-918. 
Radfar, S., Aghaie, M., Arani, M., Nooh, S., \& Saburi, A. (2013). Evaluation of Emotional Intelligence and Its Relation to the Academic Achievement in Medical Students. Tehran Students' Research Centers Network (Thrita), 2(1), 114-119.

Ringle, C. M., Wende, S., \& Will, A. (2010). Finite mixture partial least squares analysis: Methodology and numerical examples. Handbook of partial least squares (pp. 195-218): Springer.

Rivers, S. E., Brackett, M. A., Omori, M., Sickler, C., Bertoli, M. C., $\&$ Salovey, P. (2013). Emotion skills as a protective factor for risky behaviors among college students. Journal of College Student Development, 54(2), 172-183.

Salovey, P., \& Mayer, J. D. (1990). Emotional intelligence. Imagination, Cognition and Personality, 9(3), 185-211.

Seiter, L. N., \& Nelson, L. J. (2011). An Examination of Emerging Adulthood in College Students and Nonstudents in India. Journal of Adolescent Research, 26(4), 506-536.

Stewart, M. F., Chisholm, C., \& Allen, M. (2010). Academic success of first-year engineering students: emotional intelligence a predictor? Paper presented at the Proc. Conf. EE2010inspiring the next generation of engineers.

Wider, W., Mustapha, M., \& Bullare, F. B. (2015). A preliminary analysis of the perceptions of the five features of emerging adulthood: a comparison of perceived adult status among emerging adults in Malaysia. Projournal of humanities and social science, 3(1), 12-24.

Yelkikalan, N., Hacioglu, G., Kiray, A., Ezilmez, B., Soylemezoglu, E., Cetin, H., \& Ozturk, S. (2012). Emotional intelligence characteristics of students studying at various faculties and colleges of universities. European Scientific Journal, 8(8), 33-50. 